\title{
Analytical Methods
}
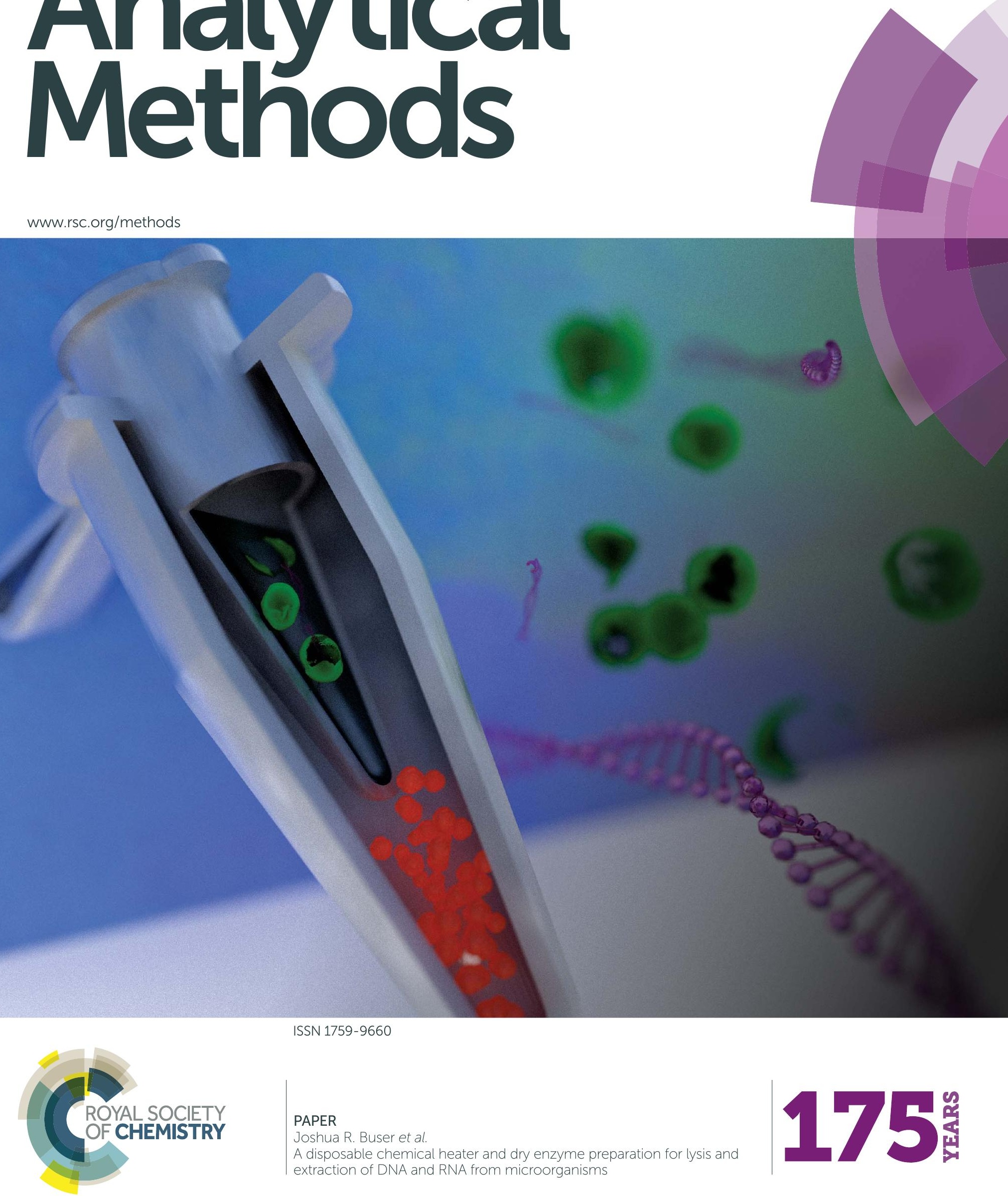

\section{PAPER}




\title{
Analytical Methods
}

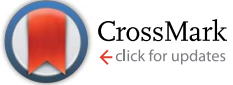

Cite this: Anal. Methods, 2016, 8, 2880

\section{A disposable chemical heater and dry enzyme preparation for lysis and extraction of DNA and RNA from microorganisms}

\author{
J. R. Buser, ${ }^{\text {a }}$ X. Zhang, ${ }^{a}$ S. A. Byrnes, ${ }^{a}$ P. D. Ladd, ${ }^{a}$ E. K. Heiniger, ${ }^{a}$ M. D. Wheeler, ${ }^{a}$ \\ J. D. Bishop, ${ }^{a}$ J. A. Englund, ${ }^{\text {bc }}$ B. Lutz, ${ }^{a}$ B. H. Weigl ${ }^{d}$ and P. Yager ${ }^{a}$
}

\begin{abstract}
Sample preparation, including bacterial lysis, remains a hurdle in the realization of complete point-of-care tests for many pathogens. Here, we developed a sample preparation methodology for enzymatic lysis and sample heating for low-resource, point-of-care applications. We show an instrument-free chemical heater system for rapid lysis of a Gram-positive bacterium (Staphylococcus aureus) and an RNA virus (human respiratory syncytial virus) using a dried lysis enzyme mixture (achromopeptidase) for $S$. aureus. After a lysis step ( $<1$ minute), lysis enzymes are heat deactivated ( $<5$ minutes) using a simple disposable chemical heater. We demonstrated that both DNA and RNA in the heat-treated sample could be directly amplified without purification, even in the presence of a clinically-obtained human nasal sample. This simple approach to dry enzyme storage and sample heating is adaptable to many applications where samples need to be lysed, including use in low-resource laboratories and in single-use or cartridgebased point-of-care diagnostic devices.
\end{abstract}

Received 12th January 2016

Accepted 1st March 2016

DOI: 10.1039/c6ay00107f

www.rsc.org/methods molecular diagnosis which can lead to identification of specific pathogens and potential drug resistances. Methicillin-resistant Staphylococcus aureus (MRSA) is a significant pathogen causing hospital- and community-acquired infections in developing and developed regions; ${ }^{11,12}$ further advancement in diagnostics which can quickly identify methicillin resistance could aid in slowing the spread of this pathogen. Nucleic acid amplification tests (NAATs), which utilize a pathogen's DNA or RNA, are commonly used in pathogen identification: polymerase chain reaction (PCR) is a widely used example. The use of NAATs for disease diagnosis offers multiple advantages including increased sensitivity, the ability to multiplex, and epidemiological tracking of disease transmission and drift via nucleic acid (NA) sequencing. These approaches, however, often require expensive equipment and highly trained personnel.

Integrated microfluidic systems, such as the Cepheid GeneXpert, provide sample-to-result diagnostics using disposable cartridges that contains the assay reagents. These cartridges are coupled with automated instrumentation to process the sample and perform the bioassay, and have been shown to expedite treatment for pathogens including Mycobacterium tuberculosis. ${ }^{\mathbf{1 3}}$ These systems, however, have significant cost, infrastructure, and maintenance commitments associated with them ${ }^{\mathbf{1 4}}$ and are most appropriate for use in well-equipped laboratories with reliable electricity. Significant advances in NAATs are still required for lower-resource settings. ${ }^{15}$

Microfluidic bioassays have the potential to expand the reach of NAATs, but sample preparation, including pathogen lysis and nucleic acid extraction, remains an underdeveloped 
aspect of microfluidics-based bioassays, especially those designed for point-of-care use. ${ }^{\mathbf{1 6}}$ Many commercially available systems that are marketed for the point-of-care are often missing sample preparation components. In 2011, Niemz et al. evaluated 13 commercially available point-of-care NAAT-based systems. All of these systems include an expensive, nondisposable component that requires mains electricity and, likely, a service contract. Additionally, less than half of these include on-device sample preparation thereby increasing the overall time and costs required for operation and limiting their usability as truly point-of-care systems. ${ }^{17}$

Enzymatic lysis has been shown to be effective in bacterial sample preparation. Some lytic enzymes are highly specialized for a specific cell type, such as lysostaphin which targets staphylococcus bacteria, ${ }^{18}$ while others are more generally applied. Lysozyme is a commonly used and well understood lytic enzyme which cleaves the peptide-disaccharide linkage of peptidoglycans in bacterial cell walls causing them to denature. ${ }^{19}$ Many Gram-negative bacteria are insensitive to lysozyme because their thick outer membrane prevents the enzyme from interacting with the inner cell wall; additionally, some Grampositive bacteria, such as $S$. aureus, are also resistant to lysozyme treatment. ${ }^{20}$ Achromopeptidase (ACP), purified from Achromobacter, was found to have bacteriolytic activity as early as the early $1970 \mathrm{~s} .{ }^{21}$ Since then, it has been widely used for the lysis of lysozyme-resistant Gram-positive bacteria such as $S$. aureus. Some MRSA diagnostic assays on the market use ACP for lysis and downstream real-time PCR for pathogen identification (e.g., the BD Gene Ohm MRSA test). Most of the assays employ ACP lysis at $37{ }^{\circ} \mathrm{C}$ for $10-20$ minutes, followed either by heat deactivation at a controlled temperature ${ }^{22}$ or $\mathrm{KOH}$ deactivation. ${ }^{23}$

Isothermal NAATs, such as loop-mediated isothermal amplification (LAMP) ${ }^{\mathbf{2 4 , 2 5}}$ and recombinase-polymerase amplification (RPA ${ }^{26}$ have received much attention recently due to their simple heating requirements. In addition, isothermal NAATs have been demonstrated on paper microfluidic platforms. ${ }^{27-29}$ Furthermore, paper microfluidics have been proven capable of automating multistep assays without external equipment. ${ }^{30}$ Precise electricity-free heaters have been developed for these applications: ${ }^{24}$ these are powered by exothermic chemical reactions and use phase change to regulate temperature. Our group has demonstrated the heating of flat-profile paper microfluidic networks using this technique. ${ }^{31,32}$

These technologies suggest GeneXpert-like molecular diagnostics are possible in low-cost, disposable devices, ${ }^{27,28}$ though many existing isothermal NAAT-based diagnostics still rely on off-device sample processing steps that will not be available in all settings. Fortunately, technologies are beginning to emerge that enable the operation of molecular diagnostics without the need for laboratory infrastructure. ${ }^{29,33}$ The multiplexable, autonomous, disposable nucleic acid amplification test (MAD NAAT) project ${ }^{31,34-39}$ aims to create a comprehensive isothermal NAAT platform that takes a biological sample as input, lyses cells, amplifies nucleic acid sequences from the lysate, and provides visual readout of the assay results. Non-electric heating options allow for regulated, elevated temperatures optimal for bioassays in environments without the need for external electrical power or batteries. ${ }^{25,31,32,40,41}$ A rapid, low-cost NAAT amenable to point-of-care diagnostics in lower-resource settings could significantly expedite identification of pathogens in people, food, and drinking water.

Here we demonstrate rapid lysis of a suspension of $S$. aureus using dry-stored ACP, followed by a rapid ( $<5$ minutes) electricity-free heat deactivation step, the output of which can be tested directly using quantitative PCR (qPCR). In addition to lysis of $S$. aureus suspended in Tris buffer, we also demonstrate direct qPCR amplification of lysed $S$. aureus suspended in a human nasal sample. Further, human respiratory syncytial virus (RSV) virions suspended in human nasal sample are heattreated without ACP and direct reverse transcriptase PCR (RT-PCR) used to quantify released RNA. In addition to the applications demonstrated, this methodology is easily adaptable to any assay that requires a temperature step at $\sim 100{ }^{\circ} \mathrm{C}$.

The chemical heaters described here were produced from common laboratory supplies with minimal tooling and production steps and could be incorporated into more complex multi-step devices for sample pretreatment prior to a bioassay. This approach, when combined with advances in point-of-care nucleic acid amplification assays, could enable sample-to-result nucleic acid detection in lower-resource settings.

\section{Materials and methods}

\section{Bacterial culture}

Staphylococcus aureus (strain RN4220 obtained from the Ferric Fang laboratory at the University of Washington) was cultured in Tryptic Soy Broth (BD Bacto, Sparks, MD, USA) at $37{ }^{\circ} \mathrm{C}$, shaking at $250 \mathrm{rpm}$. Overnight cultures were diluted $1: 100$ in fresh Tryptic Soy Broth and grown to mid-log phase $(\mathrm{OD} 600=$ 2). Cells were spun down at $10000 \mathrm{~g}$ for 3 minutes at $20{ }^{\circ} \mathrm{C}$ after growth and resuspended in the same volume of Tris buffer (10 mM Tris, pH 8.0) or Tris-EDTA (TE: $10 \mathrm{mM}$ Tris-HCl, $1 \mathrm{mM}$ EDTA, pH 8.0) buffer. Cells dilutions used the same buffer.

\section{Virus source and preparation}

Human respiratory syncytial virus (RSV, laboratory strain obtained from the University of Washington Clinical Virology Laboratory) was cultured by the UW clinical virology laboratory. Virions were aliquoted at $10^{6} \mathrm{RSV}$ copies per microliter and stored at $-80{ }^{\circ} \mathrm{C}$.

\section{ACP lysis}

$S$. aureus cell suspensions (OD600 $=2)$ were diluted in Tris or TE $1: 1000$ to $\sim 10^{6} \mathrm{cfu} \mathrm{mL}^{-1}$. The cell suspension was added to tubes pre-loaded with ACP (20 U $\mu \mathrm{L}^{-1}$ stock, Sigma A3547) to

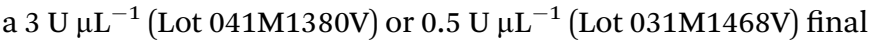
ACP concentration and mixed by gently pipetting up and down.

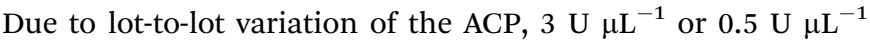
concentrations were used. The reaction was incubated at room temperature $\left(20^{\circ} \mathrm{C}\right)$ or $37^{\circ} \mathrm{C}$. ACP was deactivated by placing the tubes in a heating block (for experiments varying the heat deactivation time and temperature) or in the chemical heater (thermal profiles shown in Fig. 3). Lysate tubes were briefly spun 

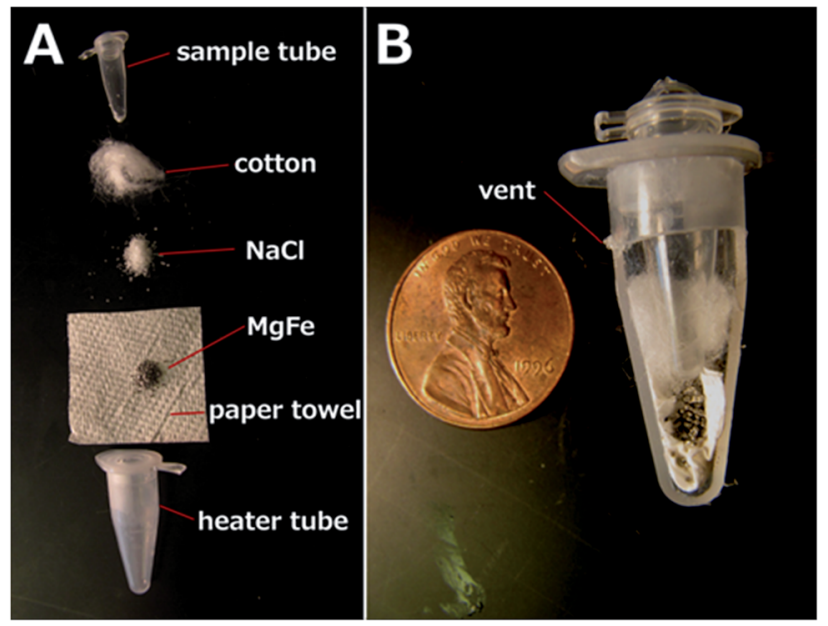

Fig. 1 Device schematic. (A) Exploded view. The paper towel was inserted into the heater tube, followed by the $\mathrm{MgFe}, \mathrm{NaCl}$, and cotton. Water was added to activate heating, after which the sample tube is inserted. (B) Assembled sectional view. The MgFe corrosion reaction heats the sample tube. Hot gasses exit the vent upon device activation.

at $3000 \mathrm{~g}$ to pull condensation down from the tube walls before conducting qPCR.

\section{ACP mixture dehydration}

In a $0.2 \mathrm{~mL}$ PCR tube, $37 \%$ trehalose (TS1M-100, Life Sciences

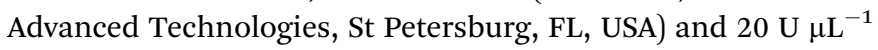
ACP were mixed together for a final trehalose concentration of $5 \%$ in the mixture and a final ACP concentration of $3{\mathrm{U} \mu \mathrm{L}^{-1} \text { or }}^{-1}$ $0.5 \mathrm{U} \mathrm{LL}^{-1}$ in the lysate (depending on the lot of ACP). The tubes were dried in a vacuum concentrator (miVac DNA, GeneVac, Stone Ridge, NY, USA) at $20^{\circ} \mathrm{C}$ for 1.5 hours, and then stored in a desiccator at $20^{\circ} \mathrm{C}$. For cell lysis, the dried ACP was rehydrated with cell suspension following the protocol for 'ACP lysis'.
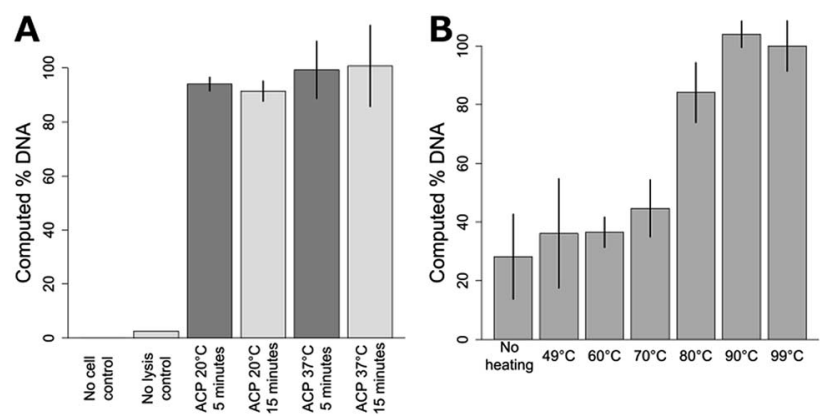

Fig. 2 Optimization of ACP enzymatic lysis and heat-deactivation. (A) Influence of varying ACP lysis time and temperature on DNA recovery. All ACP lysis conditions resulted in similar DNA recovery $(p>0.05)$. The plotted data is the mean \pm one standard deviation, with $37^{\circ} \mathrm{C} \mathrm{ACP} 15$ minute lysis set to $100 \%, n=3$ for ACP lysis conditions, $n=2$ for no cell and no lysis controls. (B) Comparison of heat deactivation temperatures for two minute ACP lysis at room temperature. Deactivation temperatures below $80^{\circ} \mathrm{C}$ reduced performance $(p<0.0001)$. Data points are mean \pm one standard deviation, $n=3$. Data was normalized to the $99{ }^{\circ} \mathrm{C}$ data, which was set to $100 \%$.

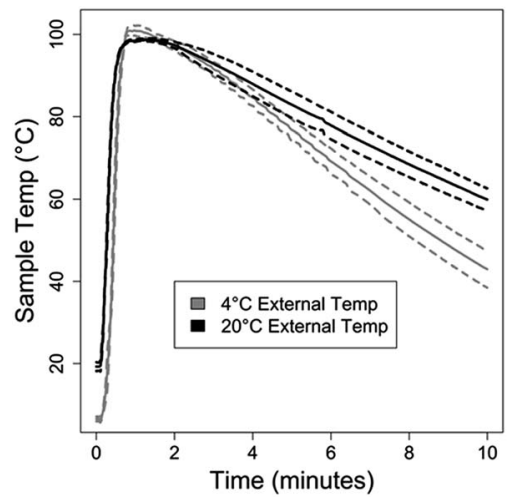

Fig. 3 Chemical heater performance in varied ambient conditions. The chemical heater was run either in laboratory conditions $\left(20^{\circ} \mathrm{C}\right)$ or in a cold room $\left(4^{\circ} \mathrm{C}\right)$. The chemical heater was designed with enough $\mathrm{MgFe}$ fuel and $\mathrm{NaCl}$ to perform well even in cold ambient conditions. Solid lines are means, dotted lines are \pm one standard deviation, $n=3$.

\section{Chemical heaters}

This type of heater is based on the exothermic reaction of a magnesium-iron alloy $(\mathrm{MgFe})$ with a solution containing sodium chloride $(\mathrm{NaCl})$. This approach is widely used to warm up portable meals ${ }^{42}$ and is capable of releasing heat very quickly. The chemical heaters feature a tube-in-tube design: the outer heater tube contains the elements necessary for the exothermic reaction; the inner tube contains the dried ACP and sample. The outer heater tube consists of a modified $1.5 \mathrm{~mL}$ snap-cap tube (89000-028, VWR, Radnor, PA, USA), separated from the cap, cut to $26 \mathrm{~mm}$ height as measured from the conical end, and with a $0.5 \mathrm{~mm}$ hole drilled in the side to serve as a vent. The separated cap was drilled with a $\frac{1}{4}$ " hole for insertion of the sample tube. A $3 \mathrm{~cm} \times 3 \mathrm{~cm}$ square of paper towel (Kleenex C-fold towels, Kimberly Clark Professional, Roswell, GA) was inserted into the heater tube, followed by $120 \mathrm{mg}$ of the solid MgFe fuel (Luxfer Magtech, Cincinnati, OH, USA), $70 \mathrm{mg}$ of $\mathrm{NaCl}$, and a portion of cotton ball $(100 \%$ cotton, Kroger, Cincinnati, OH, USA). The modified heater tube was then fitted with the modified cap and pressed into a salvaged section of a Styrofoam shipping container. The heater was activated by adding $300 \mu \mathrm{L}$ of deionized water through the $\frac{1}{4}$ " hole, into which the sample tube (981005, Qiagen, Hilden, Germany) was then inserted. Caution should be observed: the MgFe reaction reaches $100{ }^{\circ} \mathrm{C}$ quickly and produces hydrogen and steam, which should vent from the vent hole. Venting is critical to prevent pressure build-up and sample tube ejection. Sample temperature was measured with a type $\mathrm{T}$ needle thermocouple inserted into a hole drilled in the sample tube cap, recording temperature data over time with a data acquisition system (OMB-DAQ-54, Omega Engineering, Stamford, CT, USA).

\section{Bead beater}

Samples of $S$. aureus cell suspension $(800 \mu \mathrm{L})$ were added to $2 \mathrm{~mL}$ O-ring screw top tubes (02-682-558, Thermo Fisher Scientific, Waltham, MA, USA) with $800 \mathrm{mg}$ beads (9830, Research Products International Corp., Mt. Prospect, IL, USA). 

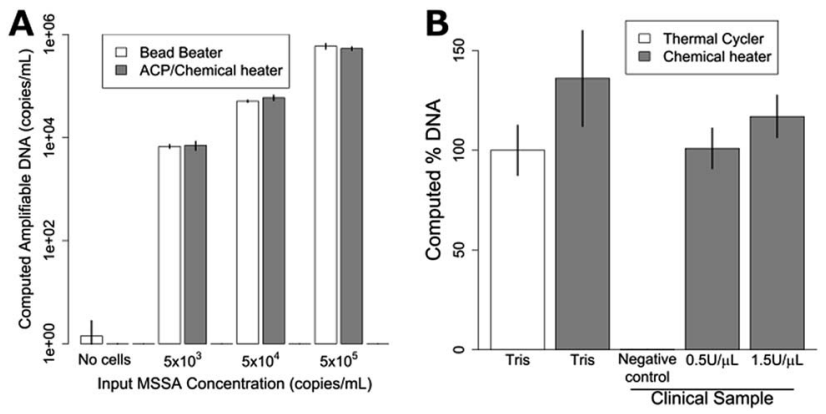

Fig. 4 Lysis of MSSA with dry ACP and chemical heat deactivation in the device of Fig. 1. (A) Lysis of various concentrations of MSSA in Tris buffer. Bead beater DNA recovery is compared to dried ACP lysis at room temperature using a chemical heater for enzyme deactivation. The chemically-heated devices perform just as well as the bead beater for all concentrations tested. Data is mean \pm one standard deviation, $n$ = 3. (B) MSSA lysis using a conventional heater (thermal cycler) and chemical heat deactivation for samples in buffer and in human nasal sample matrix. Chemical heaters perform similarly $(p=0.08)$ to thermal cycler-heated tubes for Tris samples. MSSA added to human nasal sample matrix was also successfully amplified, with no significant difference compared to the Tris buffer thermal cycler-heated data. The negative control shows DNA recovery when no MSSA is spiked in the clinical sample. The data were normalized to the Tris thermal cycler, which was set to $100 \%$. Plotted is the mean \pm one standard deviation, $n=3$.

Tubes were loaded into the bead beater (Mini-Beadbeater-8, Biospec Products, Inc., Bartlesville, OK, USA), set to "homogenize", and run for three 1 minute cycles with a 1 minute pause between cycles.

\section{qPCR}

For quantification of $S$. aureus DNA, a commercially available qPCR kit (ELITech Group, Bothell, WA, USA) was used. Samples $(2 \mu \mathrm{L})$ from the bead beater or ACP lysate were used in $20 \mu \mathrm{L}$ qPCR reactions (Rotor-Gene Q, Qiagen, Valencia, CA, USA or CFX96 Touch, Bio-Rad, Hercules, CA, USA) using: $50^{\circ} \mathrm{C}$ hold for 2 minutes, $93{ }^{\circ} \mathrm{C}$ hold for 2 minutes, 45 cycles of $93{ }^{\circ} \mathrm{C}$ for 10 seconds, $56{ }^{\circ} \mathrm{C}$ for 30 seconds, and $72{ }^{\circ} \mathrm{C}$ for 15 seconds, ending with a final elongation step at $72{ }^{\circ} \mathrm{C}$ for 5 minutes. Fluorescence data were collected during the $56{ }^{\circ} \mathrm{C}$ step using the orange channel. Genomic DNA copy numbers were determined relative to standard curve analysis using purified DNA of known copy number using the qPCR device software. The assay was sensitive down to $\sim 10$ copies of the target sequence.

\section{qRT-PCR}

For quantification of RSV RNA, UltraSense quantitative RT-PCR assay mix (Life Technologies, Carlsbad, CA, USA) was used with primer and probe sequences published previously. ${ }^{43}$ The thermal protocol used was: $50{ }^{\circ} \mathrm{C}$ hold for 15 minutes, $95{ }^{\circ} \mathrm{C}$ hold for 2 minutes, 40 cycles of $95{ }^{\circ} \mathrm{C}$ for 15 seconds and $60^{\circ} \mathrm{C}$ for 55 seconds using $20 \mu \mathrm{L}$ reactions on a CFX96 Touch (BioRad). Genomic RNA copy numbers were determined relative to standard curve analysis using control RSV RNA (American

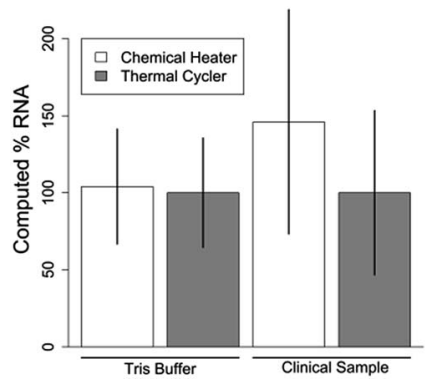

Fig. 5 Lysis of RSV in Tris and human nasal sample matrix with thermal cycler and chemical heater heat deactivation. Equal concentrations of RSV in Tris buffer or human nasal sample matrix were lysed for 5 minutes then analyzed by qRT-PCR. Output is reported by percent amplifiable RNA, with thermal cycler data set to $100 \%$. Data is mean \pm one standard deviation, $n=6$ for Tris buffer, $n=5$ for clinical sample.

Type Culture Collection (ATCC), Manassas, VA, USA) of known copy number.

\section{Clinical sample collection}

Clinical samples were collected from patients following signed parental informed consent from January to March 2015 from pediatric patients with suspected influenza infection. Nylon flocked mid-nasal swabs were collected in the hospital or emergency department for influenza and RSV testing. Each swab was placed into $750 \mu \mathrm{L}$ of phosphate buffered saline, $0.05 \%$ Tween-20, and $0.01 \%$ sodium azide. The diluted nasal swab sample was used for RT-PCR detection of influenza or RSV. Samples that were negative for either influenza or RSV were spiked with laboratory strains of RSV and MSSA to determine the impact of the sample composition on direct amplification assays. Seattle Children's Hospital Institutional Review Board approved the sample collection and analysis of specimens. Written consent was obtained from a parent or legal guardian, as approved by the Seattle Children's Institutional Review Board, with paper copies given to parent and also maintained under secure storage by the research team.

\section{Statistics}

A Student's $t$-test was performed comparing 5 - and 15 minute ACP data for 20 and $37{ }^{\circ} \mathrm{C}$ (Fig. 2A) in Excel (Microsoft, Redmond, WA, USA), comparing temperatures $\leq 70{ }^{\circ} \mathrm{C}$ to $80-99{ }^{\circ} \mathrm{C}$ (Fig. 2B), comparing fresh and dried ACP results with $10^{5} \mathrm{~S}$. aureus cells, comparing performance of the thermal cycler and chemical heater for Tris buffer samples (Fig. 4B), and comparing chemical heater and thermal cycler results for RNA recovery in Tris buffer and human nasal sample matrix (Fig. 5). Two-tailed comparisons were used, assuming the data were homoscedastic.

\section{Results and discussion}

As previously mentioned, NAATs that employ ACP lysis operated at $37{ }^{\circ} \mathrm{C}$ for $10-20$ minutes, followed by heat deactivation at a controlled temperature, have been demonstrated previously. 
Here, we compare ACP lysis at 20 and $37^{\circ} \mathrm{C}$, for 5 and 15 minute incubations, followed by heat deactivation at $99{ }^{\circ} \mathrm{C}$. As shown in Fig. 2A, the amount of recoverable DNA from $S$. aureus cells was similar for all conditions tested $(p>0.05)$. No DNA was detected for either the fresh or dried ACP no-cell control. Fig. 2B shows performance is dependent on the heat deactivation temperature, with temperatures less than $80{ }^{\circ} \mathrm{C}$ performing less well $(p<$ 0.0001 ). Lot $031 \mathrm{M} 1468 \mathrm{v}$ ACP only recovered $57 \%$ of the amplifiable DNA compared to lot $041 \mathrm{M} 1380 \mathrm{v}$ at $3 \mathrm{U}^{-1} \mathrm{~L}^{-1}$ (activity units were reported by the manufacturer, $p=0.005$.) When lot $031 \mathrm{M} 1468 \mathrm{v}$ was used at $0.5 \mathrm{U} \mu \mathrm{L}^{-1}$, the resulting lysis perfor-

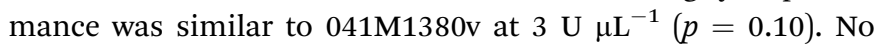
difference in lysis efficiency was observed lysing cells in Tris or TE buffer $(p=0.45)$. Heat deactivation of ACP was also found to be robust, with times from one to ten minutes leading to similar performance.

Based on these data, a chemical heater was designed to heat the sample to over $80{ }^{\circ} \mathrm{C}$ for over one minute from a range of initial ambient temperatures. Shown in Fig. 3 are temperatures measured in the lysis tube for a heater run either in our laboratory or cold room, with time-temperature profiles adequate for ACP deactivation in both cases. As shown in Fig. 3A, the chemical heater reliably exceeds $80{ }^{\circ} \mathrm{C}$, and thereby deactivates the ACP enzymes in preparation for nucleic acid amplification, even in cold ambient conditions. The heater can be expected to reliably heat the samples in warmer ambient conditions due to the nature of the exothermic reaction.

Next, the enzymatic mixture was dried down into a form that can be stored easily and that can be rehydrated by the addition of the cell suspension. Fresh and dry ACP performs similarly at room temperature with a 5 minute $95{ }^{\circ} \mathrm{C}$ deactivation step for $10^{5} \mathrm{~S}$. aureus cells $(p=0.16$.). No DNA was detected for either the fresh or dried ACP no-cell control. This dried ACP does not lose activity when stored for 4 months compared to fresh ACP $(p=0.23)$.

For lysis with dried ACP and the chemical heater, the device shown in Fig. 1 was constructed by combining the separatelycharacterized chemical heater and dry ACP tube. $S$. aureus cells were lysed in the integrated device and the lysate was directly added to a PCR reaction for quantification of the $l d h 1$ gene. Mechanical cell disruption is effective for difficult-to-lyse microorganisms, ${ }^{17}$ bead beating was therefore chosen as a technique for comparison with the prototype devices. Fig. 4A shows similar performance of the bead beater and the integrated device for each cell concentration tested. Fig. 4B reports the amount of amplifiable DNA recovered using ACP lysis with methicillin susceptible $S$. aureus (MSSA) in Tris buffer with chemical heat deactivation or thermal cycler, and also chemical heat deactivation for MSSA spiked into a patient nasal sample. Here, chemical-heater-powered deactivation of ACP performs similarly to deactivation using the thermal cycler $(p=0.16)$. The negative control shows very little target DNA is recovered when no MSSA is spiked into the patient sample. $1.5 \mathrm{U}^{-1}$ ACP concentration was tested in addition to $0.5 \mathrm{U}^{-1}$, to check whether higher concentrations of ACP would be beneficial to account for the additional complexity of the human nasal sample matrix.
With the chemical heater performing well for ACP lysis of bacteria, we wondered if it could also lyse RNA viruses. We selected RSV, an enveloped virus that contains a single segmented $15 \mathrm{~kb}$ genomic RNA fragment per virion. ${ }^{44} \mathrm{We}$ compared lysis of RSV virions in Tris buffer or in an RSVnegative human nasal sample matrix by a thermal cycler to chemical heaters. The thermal cycler and chemical heater performed nearly identically when RSV was in Tris buffer $(p=0.94$, Fig. 5). When RSV was spiked at a known concentration into a clinical sample that previously tested negative, the thermal cycler and chemical heater performed similarly as well ( $p=$ 0.62 , Fig. 5). Overall, we conclude that the chemical heater is also an effective tool for RSV lysis.

\section{Conclusions}

Here we have demonstrated effective, rapid nucleic acid extraction from $S$. aureus and RSV. The method works in the presence of a clinically-obtained human nasal sample. S. aureus is a relatively hard-to-lyse Gram-positive pathogen, so these results highlight the robustness of the lysis method. RSV is a common childhood RNA virus, showing one potential application of the lysis method to a clinically-relevant diagnostic application. This method uses dried reagents compatible with non-refrigerated storage and a disposable chemical heat source for enzyme deactivation. No additional infrastructure or external processing was required before nucleic acid amplification. The total list price for the consumables (Eppendorf tubes, paper towel, cotton balls, $\mathrm{NaCl}, \mathrm{MgFe}$ ) used to construct the prototype heaters is less than $\$ 0.41$. Purchasing these items at larger quantities will likely reduce the cost. The only tools used to build the prototype heater were a razor blade, a drill press, drill bits, a ruler, and a scale to weigh the components. In addition to being a laboratory tool that many could build themselves, it would be straightforward for a manufacturer to make modified tubes for this type of application.

This work was performed with low-resource clinical settings in mind; however, this method is a generic tool compatible with any process (lysis or not) that requires heat. Such processes include the use of proteinase $\mathrm{K}$ or $\mathrm{NaOH}$ for relatively quick cell lysis in limited-resource laboratory settings, animal facilities, or for environmental sample analysis. Heat alone is sufficient to lyse many organisms, ${ }^{45}$ to perform heat-shock antigen-antibody dissociation, ${ }^{\mathbf{4}}$ or to denature nucleic acid complexes or proteins. This method is ideal for thermal lysis ${ }^{47}$ of $E$. coli or other organisms that lyse at elevated temperature, which could enable quick screening of plasmid cultures.

We expect that this method and other sample preparation techniques in development by our group ${ }^{34,38,39}$ will help enable the expansion of the next generation of point-of-care diagnostics assays to areas without access to traditional diagnostic infrastructure.

\section{Acknowledgements}

Buser, Zhang, Byrnes, Heiniger, Wheeler, Bishop, Lutz, Weigl, and Yager were supported by DARPA DSO/BTO HR0011-11-2- 
0007, awarded to Yager. Ladd was supported by NIH 1 R01 AI 096184-01 awarded to Yager. We would like to acknowledge Anne Cent of the molecular virology laboratory for providing a laboratory RSV virus strain for experimentation, along with the team at Seattle Children's who collected the patient nasal samples, including Kirsten Lacombe, Bonnie Strelitz, Alastair Murray, and Catherine Bull, as well as all of the patients and their families who participated in the study. We would also like to acknowledge Traci Kinkel from the Ferric Fang lab at the University of Washington for providing a laboratory strain of Staphylococcus aureus. We wish to thank Shichu Huang, Tinny Liang, both of the University of Washington and Elain $\mathrm{Fu}$, now at Oregon State University, for their help in obtaining patient samples. We would also like to thank Sujatha Ramachandran for the helpful guidance regarding ACP dry storage. We thank everyone in the Yager and Lutz labs, and collaborators at UW, PATH, GE Global Research, and the ELITech Group for the support and feedback.

\section{Notes and references}

1 R. Lozano, et al., Lancet, 2013, 380, 2095-2128.

2 H. Wang, L. Dwyer-Lindgren, K. T. Lofgren, J. K. Rajaratnam, J. R. Marcus, A. Levin-Rector, C. E. Levitz, A. D. Lopez and C. J. L. Murray, Lancet, 2012, 380, 2071-2094.

3 C. J. L. Murray, et al., Lancet, 2012, 380, 2197-2223.

4 R. W. Peeling, D. Mabey, A. Herring and E. W. Hook, Nat. Rev. Microbiol., 2006, 4, S7-S19.

5 D. Litaker, S. M. Koroukian and T. E. Love, Med. Care, 2005, 43, 531-540.

6 S. Ramani and G. Kang, Curr. Opin. Infect. Dis., 2009, 22, 477482.

7 D. R. Hill and N. J. Beeching, Curr. Opin. Infect. Dis., 2010, 23, 481-487.

8 Diarrhea Causes - Mayo Clinic, http://www.mayoclinic.org/ diseases-conditions/diarrhea/basics/causes/con-200140258, accessed January 2016.

9 K. Hodges and R. Gill, Gut Microbes, 2010, 1, 4-21.

$10 \mathrm{WHO}$, Antimicrobial Resistance Fact Sheet, 2015.

11 M. Z. David and R. S. Daum, Clin. Microbiol. Rev., 2010, 23, 616-687.

12 M. A. Borg, M. de Kraker, E. Scicluna, N. van de SandeBruinsma, E. Tiemersma, J. Monen and H. Grundmann, J. Antimicrob. Chemother., 2007, 60, 1310-1315.

13 C. C. Boehme, et al., Lancet, 2011, 377, 1495-1505.

14 A. Pantoja, C. Fitzpatrick, A. Vassall, K. Weyer and K. Floyd, Eur. Respir. J., 2013, 42, 708-720.

15 UNITAID, Tuberculosis: Diagnostic Technology Landscape, World Health Organization, 2012.

16 R. Mariella, Biomed. Microdevices, 2008, 10, 777-784.

17 A. Niemz, T. M. Ferguson and D. S. Boyle, Trends Biotechnol., 2011, 29, 240-250.

18 C. M. Kusuma, J. F. Kokai-kun and S. A. Sam, Society, 2005, 49, 3256-3263.

19 D. Voet, J. G. Voet and C. W. Pratt, Fundamentals of Biochemistry, John Wiley \& Sons, Inc, 3rd edn, 2008.
20 O. Salazar and J. a. Asenjo, Biotechnol. Lett., 2007, 29, 985994.

21 T. Masaki and K. Nakamura, Agric. Biol. Chem., 1978, 42, 1443-1445.

22 S. M. Paule, D. M. Hacek, B. Kufner, K. Truchon, R. B. Thomson, K. L. Kaul, A. Robicsek and L. R. Peterson, J. Clin. Microbiol., 2007, 45, 2993-2998.

23 N. Kobayashi, H. Wu, K. Kojima, K. Taniguchi, S. Urasawa, N. Uehara, Y. Omizu, Y. Kishi, A. Yagihashi and I. Kurokawa, Epidemiol. Infect., 2009, 113, 259.

24 P. LaBarre, K. R. Hawkins, J. Gerlach, J. Wilmoth, A. Beddoe, J. Singleton, D. Boyle and B. Weigl, PLoS One, 2011, 6, e19738.

25 J. Singleton, D. Guelig, J. Buser, R. Burton, O. Edeh, K. Hawkins, B. Weigl and P. LaBarre, in IEEE Global Humanitarian Technology Conference (GHTC 2014), IEEE, 2014, pp. 721-725.

26 L. Lillis, D. Lehman, M. C. Singhal, J. Cantera, J. Singleton, P. Labarre, A. Toyama, O. Piepenburg, M. Parker, R. Wood, J. Overbaugh and D. S. Boyle, PLoS One, 2014, 9, e108189.

27 B. A. Rohrman and R. R. Richards-Kortum, Lab Chip, 2012, 12, 3082-3088.

28 J. C. Linnes, A. Fan, N. M. Rodriguez, B. Lemieux, H. Kong and C. M. Klapperich, $R S C A d v ., 2014,4$, 42245-42251.

29 N. M. Rodriguez, J. C. Linnes, A. Fan, C. K. Ellenson, N. R. Pollock and C. M. Klapperich, Anal. Chem., 2015, 87, 7872-7879.

30 E. Fu, T. Liang, P. Spicar-Mihalic, J. Houghtaling, S. Ramachandran and P. Yager, Anal. Chem., 2012, 84, 4574-4579.

31 J. Singleton, C. Zentner, J. Buser, P. Yager, P. LaBarre and B. H. Weigl, Proc. SPIE, 2013, 8615, 86150R.

32 J. R. Buser, S. Diesburg, J. Singleton, D. Guelig, J. D. Bishop, C. Zentner, R. Burton, P. LaBarre, P. Yager and B. H. Weigl, Lab Chip, 2015, 15, 4423-4432.

33 J. R. Choi, J. Hu, R. Tang, Y. Gong, S. Feng, H. Ren, T. Wen, X. Li, W. A. B. Wan Abas, B. Pingguan-Murphy and F. Xu, Lab Chip, 2015, 16, 611-621.

34 N. Panpradist, B. J. Toley, X. Zhang, S. Byrnes, J. R. Buser, J. A. Englund and B. R. Lutz, PLoS One, 2014, 9, e105786.

35 S. Dharmaraja, L. Lafleur, S. Byrnes, P. Kauffman, J. Buser, B. Toley, E. Fu, P. Yager and B. Lutz, Proc. SPIE, 2013, 8615, 86150X.

36 B. J. Toley, B. McKenzie, T. Liang, J. R. Buser, P. Yager and E. Fu, Anal. Chem., 2013, 85, 11545-11552.

37 B. J. Toley, J. A. Wang, M. Gupta, J. R. Buser, L. K. Lafleur, B. R. Lutz, E. Fu and P. Yager, Lab Chip, 2015, 15, 1432-1444.

38 J. R. Buser, A. Wollen, E. K. Heiniger, S. Byrnes, P. C. Kauffman, P. D. Ladd and P. Yager, Lab Chip, 2015, 15, 1994-1997.

39 S. A. Byrnes, J. D. Bishop, L. Lafleur, J. R. Buser, B. Lutz and P. Yager, Lab Chip, 2015, 15, 2647-2659.

40 K. G. Shah, D. Guelig, S. Diesburg, J. Buser, R. Burton, P. LaBarre, R. Richards-Kortum and B. Weigl, PLoS One, 2015, 10, e0139449.

41 C. Liu, M. G. Mauk, R. Hart, X. Qiu and H. H. Bau, Lab Chip, 2011, 11, 2686-2692. 
42 MREInfo.com - Home, http://www.mreinfo.com, accessed September 2015.

43 J. Kuypers, N. Wright and R. Morrow, J. Clin. Virol., 2004, 31, 123-129.

44 V. M. Cowton, D. R. McGivern and R. Fearns, J. Gen. Virol., 2006, 87, 1805-1821.
45 N. Casali and A. Preston, E. coli plasmid vectors: Methods and applications, Springer Science and Business Media, 2003, vol. 235.

46 J. Schüpbach and J. Böni, J. Virol. Methods, 1993, 43, 247256.

47 J. Kim, M. Johnson, P. Hill and B. K. Gale, Integr. Biol., 2009, 1, 574-586. 